\title{
Mechanism of Calcium-Dependent Inactivation of a Potassium Current in Aplysia Neuron R15: Interaction Between Calcium and Cyclic AMP
}

\author{
Richard H. Kramer, Edwin S. Levitan, ${ }^{\mathrm{a}}$ Monita P. Wilson, and Irwin B. Levitan \\ Graduate Department of Biochemistry, Brandeis University, Waltham, Massachusetts 02254
}

In the preceding paper (Kramer and Levitan, 1988), we presented evidence that an inwardly rectifying $K^{+}$current $\left(I_{R}\right)$ is inactivated by $\mathrm{Ca}^{2+}$ influx accompanying spontaneous bursting activity in the Aplysia neuron R15. In this paper we examine the mechanism that enables $\mathrm{Ca}^{2+}$ to inactivate $\mathrm{I}_{\mathrm{R}}$. Since $I_{R}$ is enhanced by cyclic AMP in neuron R15 (Drummond et al., 1980; Benson and Levitan, 1983), we examined the $\mathrm{Ca}^{2+}$-dependent inactivation of $I_{R}$ after application of either serotonin (5-HT), the adenylate cyclase activator forskolin, or a membrane-permeable cAMP analog, all agents that increase CAMP and hence the magnitude of $I_{\mathrm{R}}$. Even though more active $I_{R}$ channels are available under these conditions, less $\mathrm{Ca}^{2+}$-dependent inactivation is observed. This is contrasted with the $\mathrm{Ca}^{2+}$-dependent inactivation of the voltage-gated $\mathrm{Ca}^{2+}$ current $\left(\mathrm{I}_{\mathrm{Ca}}\right)$. Elevating cAMP enhances $I_{c a}$ in $\mathrm{R} 15$ and also increases its $\mathrm{Ca}^{2+}$-dependent inactivation. Hence the mechanisms whereby $\mathrm{Ca}^{2+}$ inactivates $I_{R}$ and $I_{C a}$ appear to differ from each other.

Elevating internal $\mathrm{Ca}^{2+}$ by repeatedly depolarizing the neuron suppresses the response of $\mathrm{I}_{\mathrm{F}}$ to brief applications of 5-HT, and speeds the relaxation of the response, suggesting that $\mathrm{Ca}^{2+}$ can interfere with the CAMP-dependent activation of $\mathrm{I}_{\mathrm{B}}$. One biochemical site where $\mathrm{Ca}^{2+}$ can reduce cellular CAMP is by activating the $\mathrm{Ca}^{2+} /$ calmodulin-sensitive form of phosphodiesterase. We have detected such enzyme activity in homogenates of Aplysia abdominal ganglia and extracts of single R15 somata. Inhibitors of the phosphodiesterase activity suppress the $\mathrm{Ca}^{2+}$-dependent inactivation of $\mathrm{I}_{\mathrm{h}}$. Finally, we have used a radioimmunoassay to measure CAMP in individual R15 somata, and have found that R15 neurons hyperpolarized for prolonged periods contain more CAMP than do R15 neurons allowed to burst, consistent with the hypothesis that $\mathrm{Ca}^{2+}$ influx reduces cAMP. Therefore we conclude that the $\mathrm{Ca}^{2+}$-dependent inactivation of $\mathrm{I}_{\mathrm{R}}$ is due to an interaction between $\mathrm{Ca}^{2+}$ and cAMP metabolism, and that stimulation of the $\mathrm{Ca}^{2+} /$ calmodulin-dependent phosphodiesterase contributes to the inactivation of $I_{R}$ in neuron R15.

\footnotetext{
Received July 16, 1987; revised Oct. 5, 1987; accepted Oct. 8, 1987.

We thank George Augustine, Robert Carlson, and John Lisman for helpful comments on the manuscript. This work was supported by NIH Grant NS17910 to I.B.L.

Correspondence should be addressed to Dr. Kramer at the above address.

${ }^{a}$ Present address: MRC Molecular Neurobiology Unit, University of Cambridge Medical School, Hills Ruad, Cambridge CB2 2QH, England.

Copyright (C) 1988 Society for Neuroscience 0270-6474/88/051804-10\$02.00/0
}

$\mathrm{Ca}^{2+}$ and cyclic AMP are well-established intracellular messengers in neurons. Studies of physiological interactions between these messengers, however, are still in their infancy. The Aplysia bursting pacemaker neuron R15 is ideal for studying such interactions because the individual roles that $\mathrm{Ca}^{2+}$ and cAMP play are well understood. Intracellular $\mathrm{Ca}^{2+}$, which increases during bursts of action potentials, regulates several ionic currents that participate in generating the bursting pattern of electrical activity (Gorman et al., 1982; Adams and Levitan, 1985; Kramer and Zucker, 1985a, b). cAMP mediates the effects of serotonin (5-HT; Drummond et al., 1980) and of the Aplysia neuropeptide egg-laying hormone (ELH; Levitan et al., 1987) on several ionic currents in neuron R15. The cAMP-mediated responses include an increase of an inwardly rectifying $\mathrm{K}^{+}$current, $I_{R}$ (Benson and Levitan, 1983), and an increase of a voltagegated $\mathrm{Ca}^{2+}$ current, $\mathrm{I}_{\mathrm{Ca}}$ (Lotshaw et al., 1986; Levitan and I evitan, 1988).

Studies in neuron $\mathrm{R} 15$ have shown that $\mathrm{Ca}^{2+}$ and cAMP do not modulate electrical activity by privately regulating different ionic currents. Rather, there are several examples where $\mathrm{Ca}^{2+}$ and cAMP converge to modulate the same ionic currents (see Kramer et al., 1988). In the preceding paper (Kramer and Levitan, 1988), we reported that $I_{R}$ is modulated by intracellular $\mathrm{Ca}^{2+}$, in addition to the enhancement by cAMP reported earlier (Drummond et al., 1980; Benson and Levitan, 1983). $\mathrm{Ca}^{2+}$ influx leads to a large and prolonged inactivation of $I_{R}$. Hence, increasing $\mathrm{Ca}^{2+}$ or cAMP results in opposite changes in the magnitude of $I_{R}$ in neuron R15. In this paper, we examine the biochemical mechanism that enables internal $\mathrm{Ca}^{2+}$ to inactivate $I_{R}$. In particular, we have explored the possibility that $\mathrm{Ca}^{3+}$ operates by interacting with cAMP metabolism.

The molecular mechanisms that enable $\mathrm{Ca}^{2+}$ and cAMP to modulate ionic currents are of great contemporary interest. All of the effects of cAMP in eukaryotic cells are thought to be due to activation of a specific cAMP-dependent protein kinase (Greengard, 1978; but see Nakamura and Gold, 1987). Indeed, this enzyme has been shown to mediate the effect of cAMP on a variety of ionic currents, including $I_{R}$ in neuron $R 15$ (for review, see Levitan, 1985). In contrast, intracellular $\mathrm{Ca}^{2+}$ may modulate ionic currents by at least 3 different mechanisms. First, $\mathrm{Ca}^{2+}$ directly regulates certain types of ion channels, such as the "maxi" $\mathrm{Ca}^{2+}$-activated $\mathrm{K}^{+}$channel (Moczydlowski and Latorre, 1983), by binding to the channel protein and allosterically affecting its ability to open and close. Second, $\mathrm{Ca}^{2+}$ may regulate ionic currents through a more indirect biochemical route by changing the phosphorylation state of ion channels. For example, $\mathrm{Ca}^{2+} /$ calmodulin-dependent protein kinases are thought 
to modulate ionic currents in Hermissenda photoreceptors (Sakakibara et al., 1986) and mammalian brain (DeLorenzo, 1984), while $\mathrm{Ca}^{2+} /$ calmodulin-dependent phosphatases may underlie $\mathrm{Ca}^{2+}$-dependent inactivation of $\mathrm{Ca}^{2+}$ currents (Eckert and Chad, 1984; Armstrong and Eckert, 1987). Finally, $\mathrm{Ca}^{2+}$ may regulate ionic currents through an even more circuitous pathway involving regulation of cAMP metabolism. $\mathrm{Ca}^{2+}$, via calmodulin, can regulate cAMP synthesis by modulating adenylate cyclase activity (Brostrom et al., 1978) and can regulate cAMP hydrolysis by activating a form of phosphodiesterase (PDE; Wolff and Brostrom, 1979). Such modulation of cAMP metabolism by internal $\mathrm{Ca}^{2+}$ is thought to be involved in the changes of electrical activity that accompany associative conditioning in Aplysia sensory neurons (Abrams et al., 1985; Ocorr et al., 1985).

In this study we have used a combined electrophysiological and biochemical approach to ask which of the above mechanisms is responsible for the $\mathrm{Ca}^{2+}$-dependent inactivation of $\mathrm{I}_{R}$. The results indicate that $\mathrm{Ca}^{2+}$ inactivates $I_{R}$ by reducing the cAMP-dependent activation of $I_{R}$. A preliminary report of this work has appeared previously (Kramer and Levitan, 1987).

\section{Materials and Methods}

All experiments were performed on neuron R15 of the abdominal ganglion of Aplysia californica. Methods of dissection, 2-electrode voltage clamping, and the composition of artificial seawater (ASW) solutions are as described in Kramer and Levitan (1988) and Kramer and Zucker (1985a). The Ca ${ }^{2+}$-dependent inactivation of $I_{R}$ was elicited by using the voltage-clamp protocol introduced in Kramer and Levitan (1988), except where noted otherwise. Ganglia were superfused continuously with saline solutions $\left(21-23^{\circ} \mathrm{C}\right)$ at $1-3 \mathrm{ml} / \mathrm{min}$. Neurotransmitters and pharmacological agents were included in the perfusing medium except for in the experiments illustrated in Figure 7. In these experiments, 3-HT was applied with pressure from the tip of a micropipette, and 1 mM phenol red was used as a marker dye to aid in visualizing the local application of 5-HT on the soma of R15.

5-HT, 3-isobutyl-1-methylxanthine (IBMX), and 8-(4-chlorophenylthio) cAMP (8-PCPT-cAMP) were obtained from Sigma. Forskolin was obtained from Calbiochem. RO-20-1724 was kindly provided by W. Burkhard, Hoffman-LaRoche. Saline solutions containing these substances were made up immediately prior to use. Forskolin and RO-201724 stock solutions were made in ethanol, and working solutions did not contain in excess of $0.2 \%$ ethanol. This concentration of ethanol had no effect on ionic currents in control experiments.

Phosphodiesterase assay. PDE assays were performed using the method of Walter and Kiger (1984) with either Aplysia abdominal ganglia or isolated R15 somata. Ganglia were homogenized in $100 \mu \mathrm{l}$ of homogenization buffer ( $50 \mathrm{~mm}$ Tris- $\mathrm{HCl}, \mathrm{pH} 8.0$ ) with a ground-glass tissue homogenizer; single somata were disrupted by sonication and vortexing in $100 \mu \mathrm{l}$ of homogenization buffer. Five microliters of the ganglion homogenate or $20 \mu \mathrm{l}$ of the single-cell homogenate were added to 100 $\mu l$ of assay buffer, consisting of $50 \mathrm{~mm} \mathrm{NaCl}, 10 \mathrm{~mm} \mathrm{MgCl}_{2}, 10 \mathrm{~mm}$ EGTA, $1 \mathrm{mg} / \mathrm{ml}$ BSA, $4 \mathrm{~mm} \beta$-mercaptoethanol, and $50 \mathrm{~mm}$ Tris- $\mathrm{HCl}$ (pH 8.0). $\mathrm{CaCl}_{2}$ was added at appropriate concentrations $(0.36-9.95$ $\mathrm{mM}$ ) to give calculated free $\mathrm{Ca}^{2+}$ concentrations of $10^{-9}-10^{-4} \mathrm{M}$. Calmodulin (Sigma), $1 \mu \mathrm{M}$, was also included in the assay medium, although the homogenates exhibited considerable $\mathrm{Ca}^{2+}$-dependent, trifluoperazine-sensitive PDE activity in the absence of exogenous calmodulin, implying a high level of endogenous calmodulin in the tissue. Reactions were initiated by the addition of $5 \mu$ l substrate containing $3 \mu \mathrm{Ci}{ }^{3} \mathrm{H}$ cAMP, $20 \mu \mathrm{M}$ CAMP, and $20 \mathrm{mM}$ AMP. Reaction mixtures were incubated for $15-20 \mathrm{~min}$ at $37^{\circ} \mathrm{C}$, and the reaction was terminated by addition of $5 \mu \mathrm{l}$ of carrier (10 mM cAMP and $10 \mathrm{mM} \mathrm{AMP}$ ) and immersion of the assay tube in a boiling water bath. A volume of $5 \mu \mathrm{l}$ was spotted onto a strip of PEI-cellulose thin-layer chromatography (TLC) sheet containing fluorescence indicator (Brinkmann Instruments) and chromatographed in an ascending system with $50 \mathrm{mM} \mathrm{KCl}$. After about $45 \mathrm{~min}$, cAMP and AMP were identified under a shortwave UV lamp, cut from the strips, eluted with $1 \mathrm{ml}$ of $100 \mathrm{mM} \mathrm{MgCl}_{2}$ in $20 \mathrm{~mm}$ Tris$\mathrm{HCl}(\mathrm{pH} 7.4)$, and then counted in a liquid-scintillation counter.

Single somata isolation. Single R 15 somata were removed from frozen
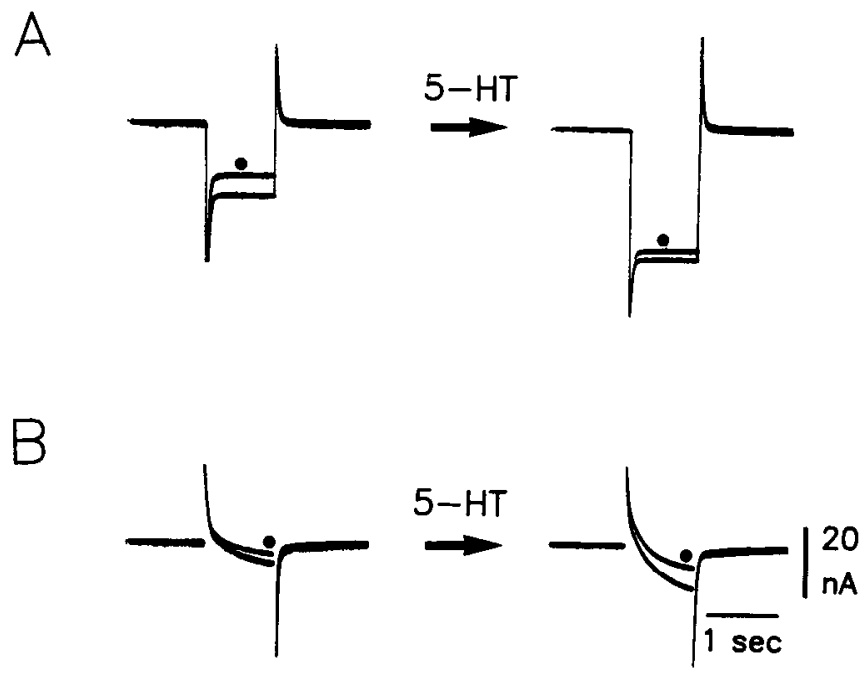

Figure 1. Effect of $50 \mu \mathrm{M} 5-\mathrm{HT}$ on $\mathrm{I}_{\mathrm{R}}, \mathrm{I}_{\mathrm{Ca}}$, and their $\mathrm{Ca}^{2+}$-dependent inactivation in R15. $A$, Membrane currents resulting from 1 sec hyperpolarizing voltage-clamp pulses from -80 to $-110 \mathrm{mV}$. The membrane current is due primarily to $I_{R}$ (see Kramer and Levitan, 1988). $B$, Membrane currents resulting from $1 \mathrm{sec}$ depolarizing pulses from -75 to $-45 \mathrm{mV}$. The inward current is due to $I_{\mathrm{Ca}}$ (Gorman et al., 1982; Kramer and Zucker, 1985a, b; Levitan and Levitan, 1988). In both $A$ and $B$, the currents were recorded before (left) and 10 min after (right) bath application of $50 \mu \mathrm{M}$ 5-HT. Each of the 4 traces shows 2 superimposed recordings: the larger current was obtained immediately before, and the smaller (partially inactivated) current (filled circles) $90 \mathrm{sec}$ after a "simulated burst" of depolarizing pulses designed to induce $\mathrm{Ca}^{2+}$ influx. The simulated burst consisted of five $150 \mathrm{msec}$ depolarizing pulses to $0 \mathrm{mV}$.

ganglia using a modification of the method of Giller and Schwartz (1971). After lowering the bath volume so that the desheathed ganglion was barely covered by saline, $2 \mathrm{ml}$ of a solution of $70 \%$ propylene glycol/ $30 \%$ normal saline $(\mathrm{vol} / \mathrm{vol})$ cooled to below $-20^{\circ} \mathrm{C}$ was dropped onto the surface. After about $5 \mathrm{sec}$, the ganglion was covered with powdered dry ice, and the microelectrodes were removed from R15. The frozen soma of R 15 was located under a dissecting microscope, broken away from the ganglion with fine forceps, and transfered to an assay tube using a needle that had been precooled by immersion in dry ice. The assay tube contained either $10 \mu \mathrm{l}$ of assay buffer below $-20^{\circ} \mathrm{C}$ for PDE experiments, or $100 \mu \mathrm{l}$ of $98 \%$ ethanol $/ 2 \% \mathrm{HCl}$ ( $\mathrm{vol} / \mathrm{vol}$ ) for determination of cAMP content by radioimmunoassay (DuPont Rianen cAMP RIA kit). Individual cells, or pools of 5 cells, were stored at $-70^{\circ} \mathrm{C}$ for PDE assays or cAMP radioimmunoassay, respectively.

\section{Results}

Effect of 5-HT on the $\mathrm{Ca}^{2+}$-dependent inactivation of $I_{R}$ Experiments using 5-HT provided the first evidence suggesting that $\mathrm{Ca}^{2+}$ does not interact directly with $I_{R}$ channels to cause their inactivation. If the inactivation of $I_{R}$ were a result of direct $\mathrm{Ca}^{2+}$ interaction with the channels, then when the magnitude of $I_{R}$ is increased, the $\mathrm{Ca}^{2+}$-dependent inactivation of $I_{R}$ should increase in parallel. One way to increase the magnitude of $I_{R}$ is to treat R15 neurons with 5-HT. As determined by noise analysis, the increase in $I_{R}$ caused by $5-H T$ is due to an increase in the number of functional channels, rather than to an increase in the probability that individual channels are open (Gunning, 1987). Hence, in the presence of increasing concentrations of 5-HT, one might expect an increasing number of $I_{R}$ channels to be inactivated by a constant influx of $\mathrm{Ca}^{2+}$. In fact, just the opposite was observed.

Figure 1 shows the effect of $50 \mu \mathrm{M} 5-\mathrm{HT}$ on $I_{R}$ and $I_{C_{a}}$, and on the $\mathrm{Ca}^{2+}$-dependent inactivation of these currents. $I_{R}$ was 

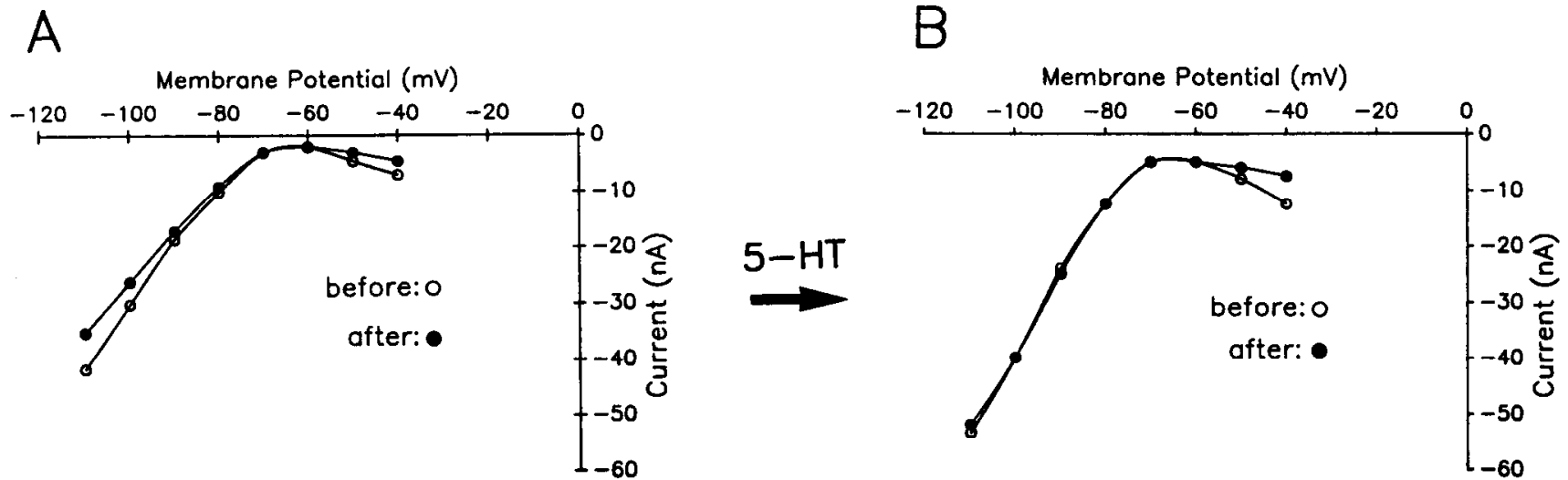

Figure 2. Effect of $50 \mu \mathrm{M} 5-\mathrm{HT}$ on the steady-state I-V curve of neuron R15. A, I-V curves obtained in normal saline. B, I-V curves obtained $15 \mathrm{~min}$ after application of $50 \mu \mathrm{M} 5-\mathrm{HT}$. In both $A$ and $B$, I-V curves were generated before and $90 \mathrm{sec}$ after a simulated burst consisting of five $150 \mathrm{msec}$ depolarizing pulses to $0 \mathrm{mV}$. Ionic currents used in constructing the I-V curves were elicited by applying $400 \mathrm{msec}$ pulses from a holding potential of $-70 \mathrm{mV}$.

elicited by applying $1 \mathrm{sec}$ hyperpolarizing voltage-clamp pulses from -80 to $-110 \mathrm{mV}$ (Fig. $1 A$ ), while $\mathrm{I}_{\mathrm{Ca}}$ was elicited by applying $1 \mathrm{sec}$ depolarizing pulses from -75 to $-45 \mathrm{mV}$ (Fig. $1 B$ ). The $\mathrm{Ca}^{2+}$-dependent inactivation of these currents was brought about ' by applying a series of voltage-clamp depolarizations that was designed to simulate the $\mathrm{Ca}^{2+}$ influx that occurs during a burst of action potentials (Kramer and Levitan, 1988). The inactivation of $I_{R}$ and $I_{C a}$ was measured $90 \mathrm{sec}$ after the end of the simulated burst.

Addition of $50 \mu \mathrm{M}$ 5-HT causes a cAMP-dependent increase in the magnitude of both $I_{R}$ and $I_{C a}$, as described previously (Benson and Levitan, 1983; Levitan and Levitan, 1988). However, $50 \mu \mathrm{M} 5$-HT has different effects on the $\mathrm{Ca}^{2+}$-dependent inactivation of these 2 currents. 5-HT reduces the $\mathrm{Ca}^{2+}$-dependent inactivation of $\mathrm{I}_{\mathrm{R}}$ caused by the simulated burst (Fig. $1 \mathrm{~A}$ ), while it enhances the $\mathrm{Ca}^{2+}$-dependent inactivation of $\mathrm{I}_{\mathrm{Ca}}$ (Fig. $1 B$ ). The effect of $5-\mathrm{HT}$ on the inactivation of $\mathrm{I}_{\mathrm{R}}$ and $\mathrm{I}_{\mathrm{Ca}}$ can best be illustrated by constructing steady-state current-voltage (I-V) curves from voltage-clamp pulse data. The inactivation of $I_{R}$ following a simulated burst is apparent at membrane potentials more negative than $-70 \mathrm{mV}$, while the inactivation of $\mathrm{I}_{\mathrm{Ca}}$ is apparent positive to $-60 \mathrm{mV}$ (Fig. $2 A$ ). The different effects of $50 \mu \mathrm{M} 5$-HT on the $\mathrm{Ca}^{2+}$-dependent inactivations of the 2 currents can be seen clearly in Figure $2 B$. The effect of 10-100 $\mu \mathrm{M} 5$-HT on the 2 currents is consistent: it reduces the inactivation of $\mathrm{I}_{\mathrm{R}}$ by $82-100 \%$, while the $\mathrm{Ca}^{2+}$-dependent inactivation of $\mathrm{I}_{\mathrm{Ca}}$ is increased $(n=7)$.

It is possible that the apparent suppression of $I_{R}$ inactivation by $5-\mathrm{HT}$ is due to a change in the kinetics of recovery from inactivation rather than to a decrease in the amount of inactivation. Figure 3 shows the recovery of $I_{R}$ and $I_{C a}$ from inactivation after a simulated burst. The peak inactivation of $I_{R}$ following a burst in normal saline is normally delayed by $60-90$ sec. In the example shown in Figure $3 A$, the small degree of $I_{R}$
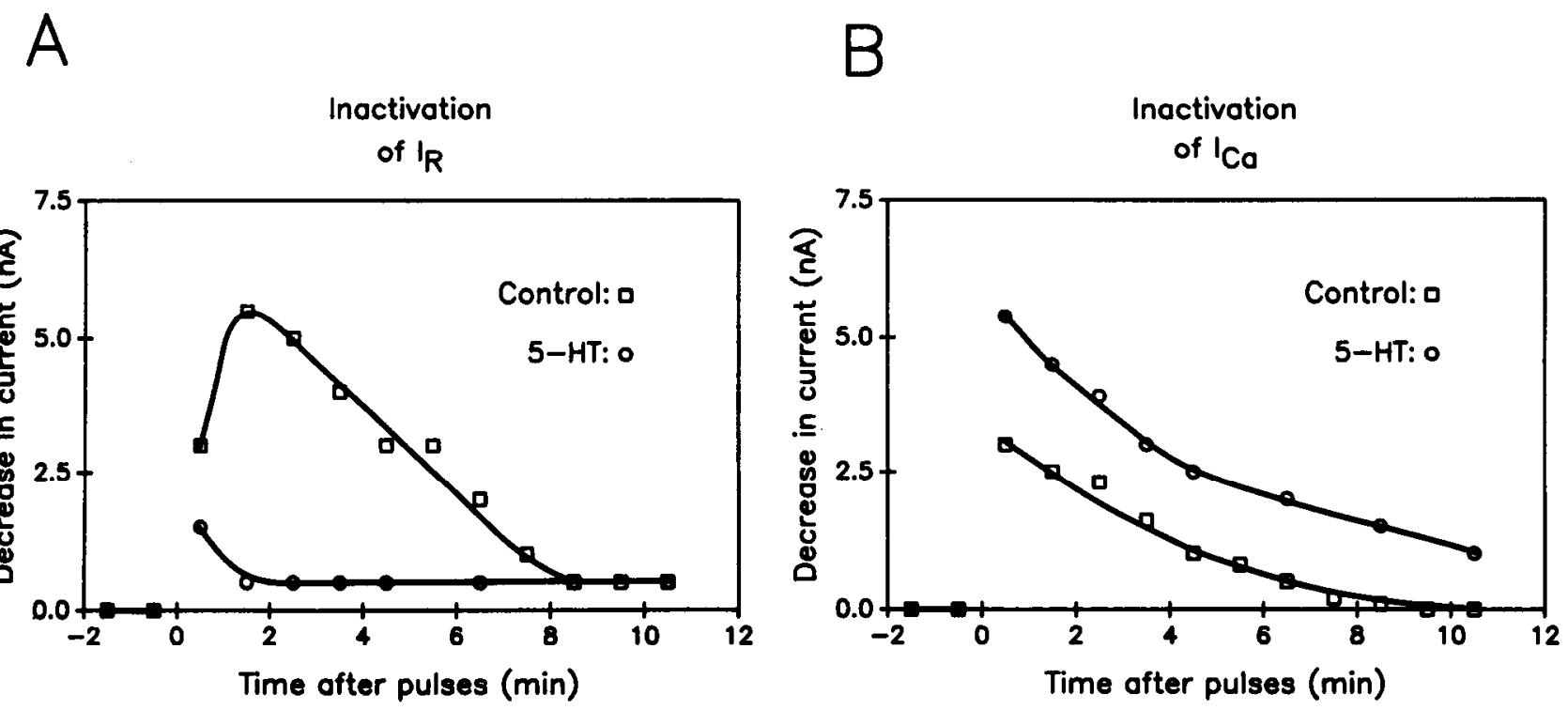

Figure 3. Kinetics of recovery from $\mathrm{Ca}^{2+}$-dependent inactivation in normal (squares) and $50 \mu \mathrm{M}$-HT (circles) saline. $A$, Recovery of $\mathrm{I}_{\mathrm{R}}$ from inactivation induced by a simulated burst. $\mathrm{I}_{\mathrm{R}}$ was elicited by applying $400 \mathrm{msec}$ pulses from -75 to $-115 \mathrm{mV}$. $B$, Recovery of $\mathrm{I}_{\mathrm{Ca}}$ from inactivation induced by a simulated burst. $\mathrm{I}_{\mathrm{Ca}}$ was elicited by applying $400 \mathrm{msec}$ pulse from -75 to $-45 \mathrm{mV}$. The simulated bursts in $A$ and $B$ were applied at time 0 , and consisted of five $150 \mathrm{msec}$ pulses to $0 \mathrm{mV}$. 

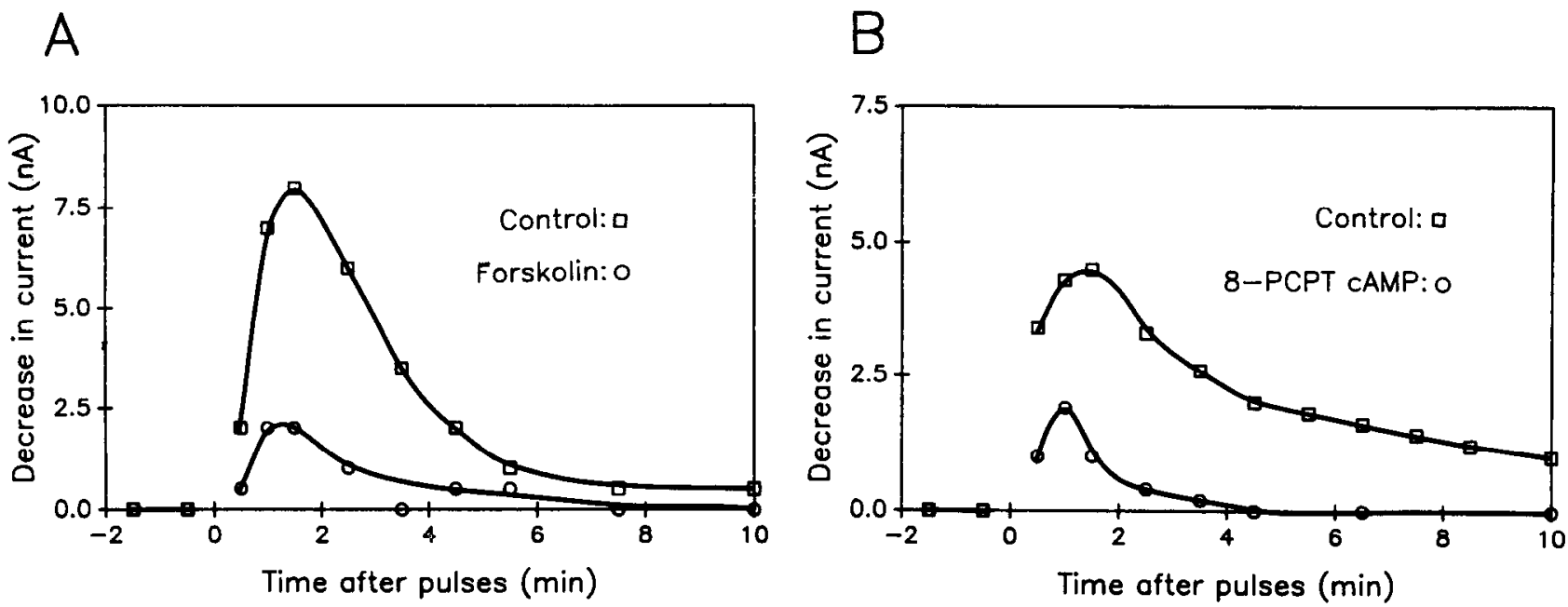

Figure 4. Effect of forskolin and 8-PCPT-cAMP on the inactivation of $\mathrm{I}_{\mathrm{R}}$. A, Time course of $\mathrm{I}_{\mathrm{R}}$ inactivation in normal saline (control) and 30 min after application of $100 \mu \mathrm{M}$ forskolin. $B$, Time course of $I_{R}$ inactivation in normal saline (control) and $90 \mathrm{~min}$ after application of $1 \mathrm{mM}$ 8-PCPT-cAMP. $I_{R}$ was measured as in Figure 3. The simulated burst given at time 0 consisted of five $150 \mathrm{msec}$ pulses to $0 \mathrm{mV}$.

inactivation measured in $50 \mu \mathrm{M} 5$-HT does not exhibit a delay, but is maximal immediately after the end of the burst. This result, however, was quite variable. In some experiments, the residual $I_{R}$ inactivation observed in $50 \mu \mathrm{M} 5-\mathrm{HT}$ exhibited no delay $(n=3)$, while in other experiments $50 \mu \mathrm{M}$ 5-HT seemed to scale down the inactivation of $I_{R}$ without changing the recovery kinetics $(n=4)$. In contrast, 5-HT increases the $\mathrm{Ca}^{2+}$ dependent inactivation of $\mathrm{I}_{\mathrm{Ca}}$ without changing the kinetics of its recovery from inactivation (Fig. $3 B$ ).

Effect of forskolin and 8-PCPT-cAMP on the inactivation of $I_{R}$ The above results demonstrate that $5-\mathrm{HT}$ can reduce the $\mathrm{Ca}^{2}$ dependent inactivation of $I_{R}$, even though 5-HT increases the number of $I_{R}$ channels available to be inactivated, and even though the $\mathrm{Ca}^{2+}$ current (and hence $\mathrm{Ca}^{2+}$ influx during the burst) is increased by 5-HT. Since 5-HT stimulates an adenylate cyclase in R15 (Levitan, 1978), leading to an increase in the level of cAMP (Cedar and Schwartz, 1972; Levitan and Drummond, 1980), we postulated that the reduction in $\mathrm{Ca}^{2+}$-dependent inactivation of $I_{R}$ elicited by $5-H T$ was mediated by cAMP. To test this hypothesis, the $\mathrm{Ca}^{2+}$-dependent inactivation of $I_{R}$ was measured after application of forskolin (Fig. 4A), which directly activates adenylate cyclase (Seamon et al., 1981). Addition of $100 \mu \mathrm{M}$ forskolin reduces the $\mathrm{Ca}^{2+}$-dependent inactivation of $\mathrm{I}_{\mathrm{R}}$ by $75-94 \%(n=3)$. In order to test whether an increase in cAMP per se can reduce the $\mathrm{Ca}^{2+}$-dependent inactivation of $I_{R}$, the inactivation of $I_{R}$ was measured after application of the membrane-permeable analog 8-PCPT-cAMP (Fig. 4B). Addition of $1 \mathrm{mM} 8$-PCPT-cAMP reduces the $\mathrm{Ca}^{2+}$-dependent inactivation of $\mathrm{I}_{\mathrm{R}}$ by $55-83 \%(n=3)$. Hence increasing cAMP in $\mathrm{R} 15$ can suppress the $\mathrm{Ca}^{2+}$-dependent inactivation of $I_{R}$.

\section{Sensitivity of the $\mathrm{Ca}^{2+}$-dependent inactivation of $I_{R}$ to 5-HT}

Only high concentrations of 5-HT reduce the $\mathrm{Ca}^{2+}$-dependent inactivation of $I_{R}$ in neuron $\mathrm{R} 15$. Figure $5 A$ shows dose-response curves of the effect of 5-HT on $I_{R}$ both before and 90 scc after a simulated burst. Increasing concentrations of 5-HT result in an increase in the amplitude of $I_{R}$, up to a saturating concentration of 1-10 $\mu \mathrm{M}$. Higher 5-HT concentrations produce no further increase of $\mathrm{I}_{\mathrm{R}}$. The curve of Figure $5 B$ shows the decrease in $I_{R}$ resulting from the simulated burst as a function of 5-HT concentration, taken from the difference between the 2 curves of Figure $5 \mathrm{~A}$. In contrast to the cAMP-dependent activation of $I_{R}$ by 5-HT, the $\mathrm{Ca}^{2+}$-dependent inactivation of $I_{R}$ increases only up to a 5-HT concentration of between 1 and 10 $\mu \mathrm{M}$, and drops dramatically at higher concentrations. Thus, it is only at saturating concentrations of 5-HT that the inhibition of $\mathrm{Ca}^{2+}$-dependent inactivation begins to occur. At less than saturating 5-HT concentrations, a nearly constant fraction of the total magnitude of $I_{R}$ is inactivated by depolarizing pulses (Fig. 5C). Above $1 \mu \mathrm{M}$ 5-HT, there is an abrupt decrease in the fraction of $I_{R}$ inactivated by $\mathrm{Ca}^{2}$ influx.

These results demonstrate that concentrations of 5-HT that result in a maximal activation of $I_{R}$ reduce the ability of intracellular $\mathrm{Ca}^{2+}$ to inactivate $I_{R}$. This observation seems to be inconsistent with a direct action of $\mathrm{Ca}^{2+}$ on $\mathrm{I}_{\mathrm{R}}$ channels. One scenario that would better explain the results is that $\mathrm{Ca}^{2+}$ counteracts the cAMP-dependent activation of $I_{R}$, and, at high levels of cAMP, the effect of $\mathrm{Ca}^{2+}$ is overwhelmed. We have considered an alternative explanation, however.

It is known that the $\mathrm{AMP}$-dependent modulation of $I_{R}$ is duc to phosphorylation of some protein substrate, possibly the $I_{R}$ channel itself (Lemos et al., 1986). Perhaps $\mathrm{Ca}^{2+}$ does interact directly with $I_{R}$ channels, but phosphorylated $I_{R}$ channels are insensitive to $\mathrm{Ca}^{2+}$-dependent inactivation. Two observations argue against this hypothesis. First, the $\mathrm{Ca}^{2+}$-dependent inactivation of $I_{R}$ is actually enhanced by addition of up to $1 \mu \mathrm{M}$ 5-HT, suggesting that modulated channels recruited by 5-HT can be inactivated. Second, the suppressive effect of high concentrations of 5-HT on inactivation can be overcome with a very large influx of $\mathrm{Ca}^{2+}$, as shown in Figure 6. In this experiment, the amplitude of the inward current elicited by hyperpolarizing pulses increased from 18 to $48 \mathrm{nA}$ following addition of $50 \mu \mathrm{M} 5-\mathrm{HT}$, indicating an enhancement of $I_{R}$. Under these conditions, a single burst of depolarizing pulses would produce little inactivation of $I_{R}$ (e.g., see Figs. 1-3, 5). At the arrow (Fig. 6 , the neuron was released from voltage-clamp, and spontaneously fired bursts of action potentials. After 5 min of continuous bursting activity, the neuron was voltage-clamped once again. The hyperpolarizing pulses now elicited only $28 \mathrm{nA}$ of 

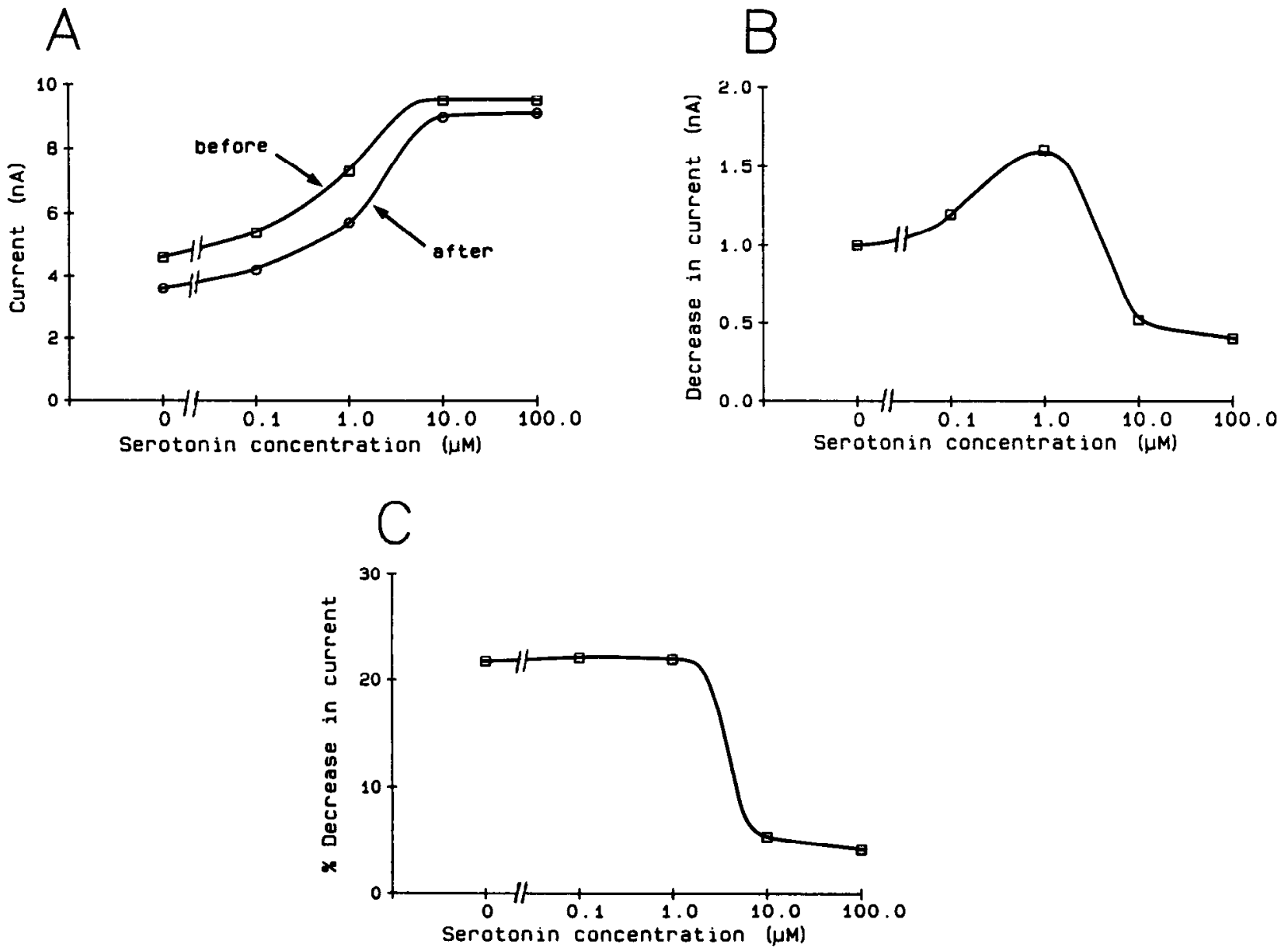

Figure 5. Dose-response curves of 5-HT action on $\mathrm{I}_{\mathrm{R}} . A$, Activation of $\mathrm{I}_{\mathrm{R}}$ as a function of 5-HT concentration. Currents were elicited by applying $400 \mathrm{msec}$ pulses from -75 to $-115 \mathrm{mV}$ before and $90 \mathrm{sec}$ after simulated bursts in saline containing $0-100 \mu \mathrm{M} 5-\mathrm{HT}$. $B$, Inactivation of $\mathrm{I}_{\mathrm{R}}$ as a function of 5-HT concentration. The decrease in current resulting from the simulated burst is taken as the difference between the 2 curves shown in $A$. $C$. Percentage of $\mathrm{I}_{\mathrm{R}}$ inactivated as a function of 5-HT concentration. Data points show the decrease in current (as in $B$ ) divided by the current elicited before the simulated burst.

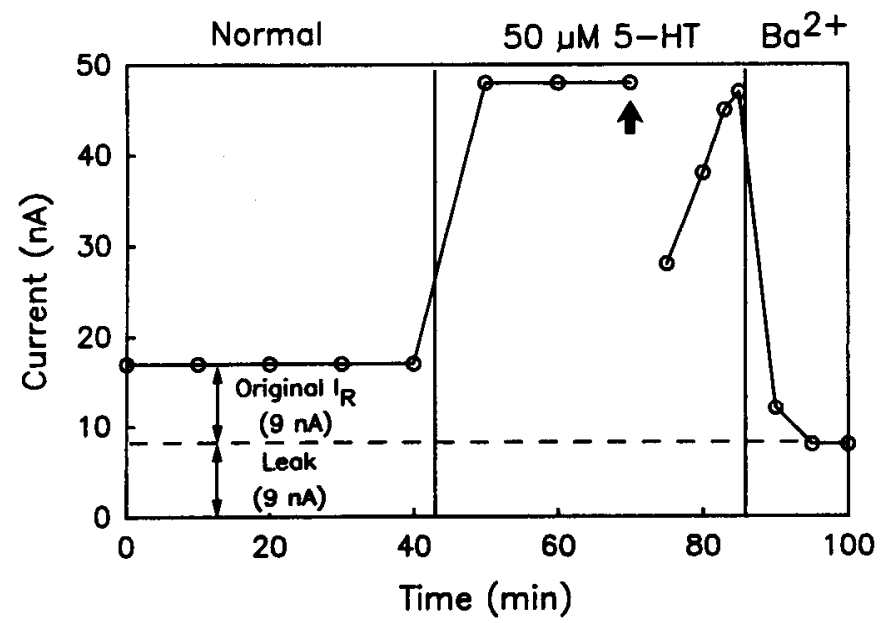

Figure 6. Suppression of $\mathrm{I}_{\mathrm{R}}$ inactivation by 5-HT can be overcome with a large influx of $\mathrm{Ca}^{2+}$. Current in normal saline, after addition of $50 \mu \mathrm{M} 5-\mathrm{HT}$, and after addition of $1 \mathrm{mM} \mathrm{Ba}^{2+}$. At the bold arrow, the cell was released from voltagc-clamp and fired bursts of spikes for 5 min; then the voltage-clamp was turned on once again. Note the inactivation of $I_{R}$ induced by the prolonged bursting activity. Currents were elicited by applying $400 \mathrm{msec}$ pulses from -75 to $-110 \mathrm{mV}$. The dashed line indicates the leak current present after addition of $\mathrm{Ba}^{2+}$. current, indicating that $20 \mathrm{nA}$ of $\mathrm{I}_{\mathrm{R}}$ was inactivated by the bursting activity. After recovery from the bursts, $1 \mathrm{mM} \mathrm{Ba}^{2+}$ was added to block all of the $I_{R}$ (Benson and Levitan, 1983; Kramer and Levitan, 1988), revealing a residual leak current of $9 \mathrm{nA}$. Hence, only about $9 \mathrm{nA}$ of the initial $18 \mathrm{nA}$ of current present before 5-HT application was $I_{R}$, but the prolonged bursting activity inactivated $20 \mathrm{nA}$ of current. Therefore, at least a portion of the $I_{R}$ inactivated by the bursts must have been recruited by $5-\mathrm{HT}$, implying that the modulated channels are indeed susceptible to $\mathrm{Ca}^{2+}$-dependent inactivation.

\section{Internal $\mathrm{Ca}^{2+}$ antagonizes the response of $\mathrm{R} 15$ to 5-HT}

There is an additional consequence of the apparent interaction between $\mathrm{Ca}^{2+}$ and cAMP in $\mathrm{R} 15$, as illustrated in Figure 7. In the experiments discussed above, we examined the effect of $\mathrm{Ca}^{2+}$ on $I_{R}$ in the presence of a given concentration of 5-HT, after the cAMP-dependent activation of $I_{R}$ had reached steady state. In the experiment illustrated in Figure 7, we examined the effect of internal $\mathrm{Ca}^{2+}$ on the activation of $\mathrm{I}_{\mathrm{R}}$ brought about by a transient application of 5-HT. 5-HT was applied transiently as follows: A micropipette (tip diameter, about $10 \mu \mathrm{m}$ ) filled with $100 \mu \mathrm{M}$ 5-HT was positioned $300 \mu \mathrm{M}$ from R15 during cach puff, and was removed from the recording chamber after each 

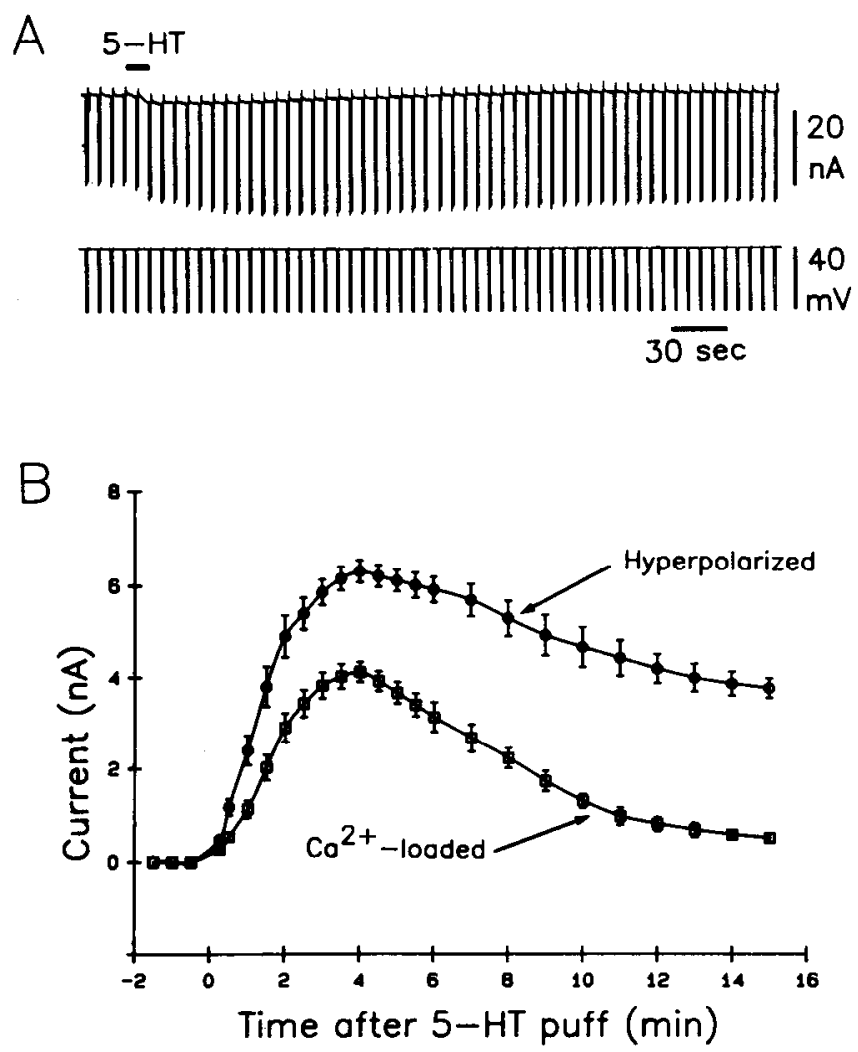

Figure 7. $\mathrm{Ca}^{2+}$ influx reduces the activation of $\mathrm{I}_{\mathrm{R}}$ by 5-HT. A, Example of modulation of $I_{R}$ by local application of a $10 \mathrm{sec}$ "puff" of $100 \mu \mathrm{M}$ 5 -HT at the soma of R15. Currents were elicited by applying $800 \mathrm{msec}$ pulses fiom -80 to $-120 \mathrm{mV}$. $B, 5-\mathrm{HT}$ responses in an $\mathrm{R} 15$ continuously hyperpolarized negative to $-80 \mathrm{mV}$ or " $\mathrm{Ca}^{2+}$-loaded" by applying $150 \mathrm{msec}$ pulses to $-5 \mathrm{mV}$ every $5 \mathrm{sec}$. These 2 treatments were alternated, and the $I_{R}$ was allowed to reach steady state in each of the 2 conditions before the 5-HT puff was applied. Data represent mean $\pm S E M$ of the increase in $I_{R}$ elicited by three $10 \mathrm{sec}$ puffs of 100 $\mu \mathrm{M} 5$-HT delivered to an R 15 in each of the 2 conditions. $I_{R}$ was measured by applying $400 \mathrm{msec}$ pulses from -80 to $-120 \mathrm{mV}$.

puff was complete. The 5-HT puff was applied to an R 15 neuron that was either continuously voltage-clamped to a hyperpolarized membrane potential $(-80 \mathrm{mV})$ to prevent $\mathrm{Ca}^{2+}$ influx through voltage-gated $\mathrm{Ca}^{2+}$ channels, or periodically depolarized to $0 \mathrm{mV}$ to induce $\mathrm{Ca}^{2+}$ influx. $\mathrm{I}_{\mathrm{R}}$ was measured at $5 \mathrm{sec}$ intervals by hyperpolarizing the cell from -80 to $-115 \mathrm{mV}$ (Fig. 7A). The 5-HT puff results in a prolonged increase in $\mathrm{I}_{\mathrm{R}}$ when the cell is kept hyperpolarized to prevent $\mathrm{Ca}^{2+}$ influx. In contrast, the response of $I_{R}$ to the 5-HT puff is smaller, and relaxes more rapidly, when the neuron is "loaded" with $\mathrm{Ca}^{2+}$ by repeated depolarizations. Figure $7 B$ shows a summary of the results from 6 puffs of 5-HT, alternately delivered to R15 in the hyperpolarized or the $\mathrm{Ca}^{2+}$-loaded state. The peak increase of $\mathrm{I}_{\mathrm{R}}$ induced by the 5-HT puff in the $\mathrm{Ca}^{2+}$-loaded state is only $66 \%$ as large as that in the hyperpolarized state. In addition, $I_{R}$ recovers more quickly to its initial amplitude when 5-HT is applied in the $\mathrm{Ca}^{2+}$-loaded state. Similar results are obtained when $100 \mu \mathrm{M}$ egg-laying hormone (ELH), instead of 5-HT, is puffed onto the neuron. Hence, $\mathrm{Ca}^{2+}$-loading antagonizes the response of $R 15$ to neurotransmitters whose effects are mediated by cAMP, suggesting once again that $\mathrm{Ca}^{2+}$ interacts with cAMP metabolism.

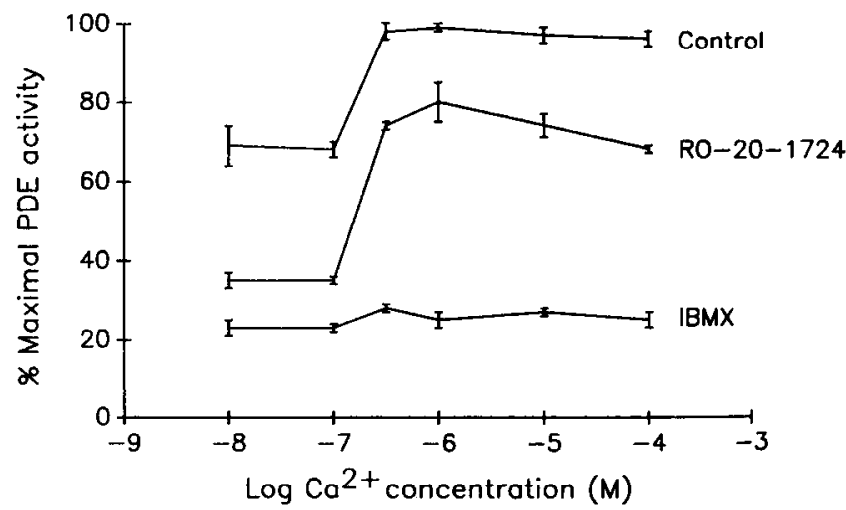

Figure 8. Phosphodiesterase activity in abdominal ganglion homogenates. PDE activity measured as the degradation of ${ }^{3} \mathrm{H}$-cAMP in buffer containing $10^{-8}-10^{-4} \mathrm{M} \mathrm{Ca}^{2+}$. Assay was performed in control assay buffer, assay buffer containing $100 \mu \mathrm{M}$ RO-20-1724, or assay buffer containing $100 \mu \mathrm{M}$ IBMX. Data are normalized with respect to maximal PDE activity (control assay at $10^{-6} \mathbf{M ~ C a}^{2+}$ ). Error bars represent range of results from 2 separate assays.

\section{$\mathrm{Ca}^{2+}$-sensitive phosphodiesterase activity}

We have focused our biochemical studies on one locus at which $\mathrm{Ca}^{2+}$ could regulate cAMP levels and potentially lead to a decrease in the magnitude of $\mathrm{I}_{\mathrm{R}}$ : the $\mathrm{Ca}^{2+} /$ calmodulin-activated form of PDE. We have detected both $\mathrm{Ca}^{2+}$-sensitive and $\mathrm{Ca}^{2+}$ independent PDE activity in homogenates of Aplysia abdominal ganglia (Fig. 8). In control assay buffer, about $70 \%$ of the total PDE activity in the homogenate is apparent below $10^{-7} \mathrm{M}$ free $\mathrm{Ca}^{2+}\left(\mathrm{Ca}^{2+}\right.$-independent PDE), while the remaining 30\% is stimulated by increasing $\mathrm{Ca}^{2+}$ to $5 \times 10^{-7} \mathrm{M}$ or higher concentrations $\left(\mathrm{Ca}^{2+}\right.$-sensitive PDE). Almost half of the $\mathrm{Ca}^{2+}$-independent PDE

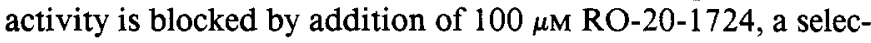
tive inhibitor of a form of $\mathrm{Ca}^{2+}$-independent PDE in mammalian tissue (Tanner et al., 1986), while the $\mathrm{Ca}^{2+}$-stimulated PDE is unaffected (Fig. 8). In contrast, $100 \mu \mathrm{M}$ IBMX blocks most of the PDE activity below $10^{-7} \mathrm{M} \mathrm{Ca}^{2+}$, and completely eliminates PDE activity stimulated by higher $\mathrm{Ca}^{2+}$ concentrations. Addition of $150 \mu \mathrm{M}$ trifluoperizine, a calmodulin inhibitor (Weiss and Levin, 1978), blocks all of the $\mathrm{Ca}^{2+}$-stimulated, and about half of the $\mathrm{Ca}^{2+}$-independent, $\mathrm{PDE}$ activity in the ganglion homogenate (data not shown).

The 2 forms of PDE activity can also be detected in extracts from single, isolated R15 somata (Fig. 9). In these experiments, the activity of $\mathrm{Ca}^{2+}$-independent PDE was taken as the rate of cAMP degradation in $10^{-9} \mathrm{M} \mathrm{Ca}^{2+}$ (Fig. 9A). The activity of $\mathrm{Ca}^{2+}$-sensitive PDE was taken as the difference in the rates of cAMP degradation in the presence of $10^{-4} \mathrm{M} \mathrm{Ca}^{2+}$ and $10^{-9} \mathrm{M}$ $\mathrm{Ca}^{2+}$, with $100 \mu \mathrm{M}$ RO-20-1724 added to reduce the background $\mathrm{Ca}^{2+}$-independent activity (Fig. $9 B$ ). In assays from $4 \mathrm{R} 15$ somata, the $\mathrm{Ca}^{2+}$-sensitive PDE accounted for $31 \pm 7 \%$ of the total measured PDE activity, while the $\mathrm{Ca}^{2+}$-independent PDE accounted for the remaining $69 \pm 7 \%$. Hence, R15 exhibits $\mathrm{Ca}^{2+}$-sensitive and $\mathrm{Ca}^{2+}$-independent PDE activities in about the same proportions measured in whole abdominal ganglia.

\section{Effects of PDE inhibitors on the Ca ${ }^{2+}$-dependent inactivation of $I_{R}$}

If $\mathrm{Ca}^{2+}$-dependent stimulation of PDE is responsible for the inactivation of $I_{R}$, then the inactivation should be blocked by addition of PDE inhibitors. Figure 10 shows the effect of IBMX 

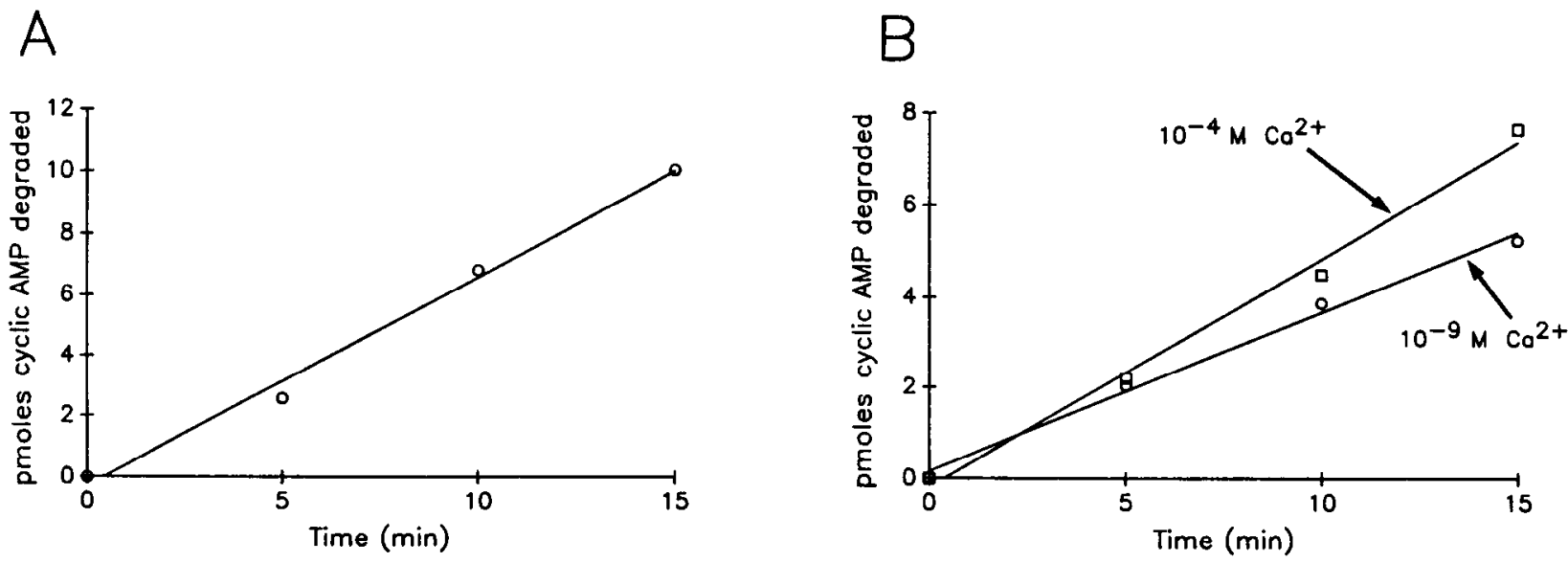

Figure 9. PDE activity in extracts of an $\mathrm{R} 15$ soma. $A, \mathrm{Ca}^{2+}$-independent $\mathrm{PDE}$ activity measured in control buffer containing $10^{-9} \mathrm{M} \mathrm{Ca}{ }^{2+} . B$, $\mathrm{Ca}^{2+}$-sensitive PDE activity in assay buffer containing $10^{-4} \mathrm{M} \mathrm{Ca}^{2+}$ and $10^{-9} \mathrm{M} \mathrm{Ca}^{2+}, \mathrm{KO}-20-1724,100 \mu \mathrm{M}$, was included to suppress background $\mathrm{Ca}^{2+}$-independent PDE activity. Linear regression lines fitted to the data in both $A$ and $B$ were used to determine reaction rates.

on the $\mathrm{Ca}^{2+}$-dependent inactivation of $\mathrm{I}_{\mathrm{R}}$. The standard voltageclamp paradigm, consisting of bursts of depolarizing pulses, was used to induce the $\mathrm{Ca}^{2+}$-dependent inactivation of $\mathrm{I}_{\mathrm{R}}$ at $20 \mathrm{~min}$ intervals. Current-voltage curves were obtained both before and $90 \mathrm{sec}$ after each burst, providing a measure of $I_{R}$ and of the $\mathrm{Ca}^{2+}$-dependent inactivation of $\mathrm{I}_{\mathrm{R}}$ (see Kramer and Levitan, 1988). IBMX induces a small increase in $I_{R}$, presumably by causing a small increase in cAMP (Fig. 10, top). Furthermore, addition of IBMX results in a reversible decrease in the inac-

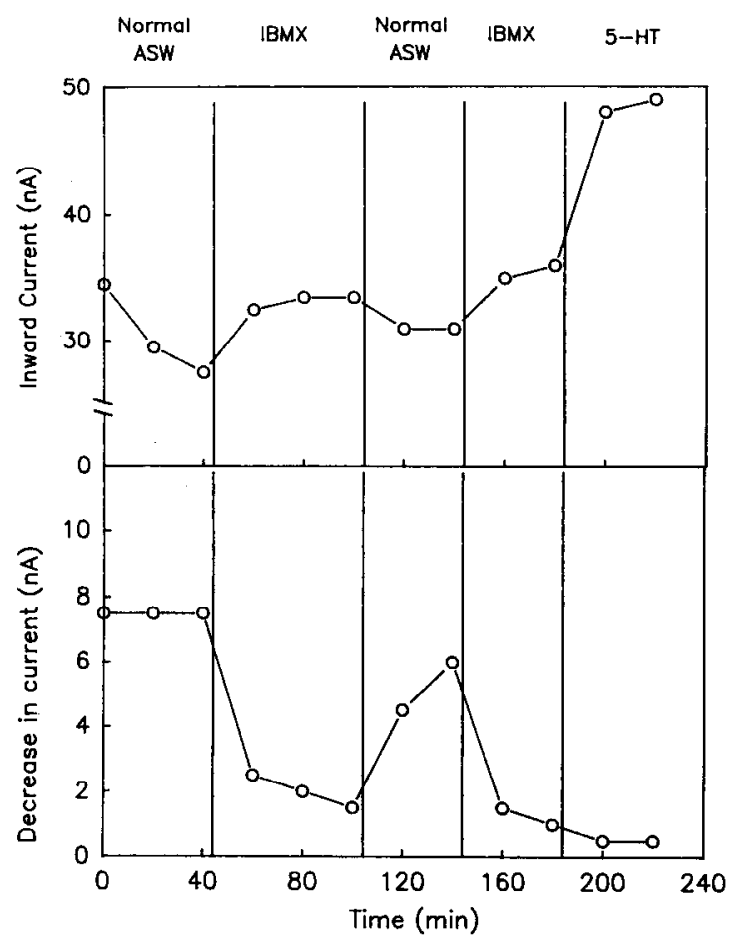

Figure 10. Effect of IBMX on $\mathrm{Ca}^{2+}$-dependent inactivation of $I_{R} \cdot I_{R}$ (top) and the inactivation of $\mathrm{I}_{\mathrm{R}}$ elicited by simulated bursts (bottom) were measured at 20 min intervals. Addition of $1 \mathrm{mM}$ IBMX reversibly suppresses the inactivation of $I_{R} \cdot 5-H T, 50 \mu \mathrm{M}$, was added at the end of the experiment to determine whether IBMX had saturated the activation of $I_{R}$. $I_{R}$ was measured by applying $400 \mathrm{msec}$ pulses from -75 to $-115 \mathrm{mV}$. tivation of $I_{R}$ (Fig. 10, bottom). At the end of the experiment, $50 \mu \mathrm{M} 5-\mathrm{HT}$ was added to the bathing medium, inducing a large increase in $I_{R}$. This demonstrates that the cAMP-dependent activation of $I_{R}$ was not saturated by the IBMX alone. Thus, in contrast to the effects of 5-HT, forskolin, and 8-PCPT-cAMP, the inhibition of inactivation by IBMX does not seem to be caused by greatly increasing the level of cAMP in the neuron. We propose that the inhibition of inactivation by IBMX is due to direct inhibition of the $\mathrm{Ca}^{2+}$-sensitive PDE per se.

We also tested the effect of RO-20-1724 on the $\mathrm{Ca}^{2+}$-dependent inactivation of $I_{R}$. Addition of $100 \mu \mathrm{M}$ RO-20-1724 results in an increase in $I_{R}$ (Fig. 11, top), but only at higher concentrations (300 $\mu \mathrm{M}$ RO-20-1724) does it begin to reduce the inactivation of $I_{R}$ (Fig. 11 , bottom). The large increase of $I_{R}$ and corresponding decrease of inactivation at $300 \mu \mathrm{M} \mathrm{RO}-20-1724$ suggest that the 2 phenomcna may be caused by the same factor, namely, an increase in cAMP. Hence, it seems likely that high RO-20-1724, like high 5-HT, inhibits the inactivation of $I_{R}$ by greatly increasing the level of cAMP in the neuron. Thus, we propose that RO-20-1724 leads indirectly to an inhibition of $\mathrm{Ca}^{2+}$ inactivation, in accord with the finding that $\mathrm{RO}-20-1724$ inhibits the $\mathrm{Ca}^{2+}$-independent, but not the $\mathrm{Ca}^{2+}$-sensitive, PDE.

Finally, we tested directly whether $\mathrm{Ca}^{2+}$ influx during bursting activity regulates the level of cAMP in neuron R15. Figure 12 shows the results of a series of radioimmunoassays that were performed on R15 somata that were rapidly frozen and isolated from abdominal ganglia. The R15 neurons were either allowed to burst continuously for $20 \mathrm{~min}$, or hyperpolarized to a potential negative to $-75 \mathrm{mV}$ under voltage-clamp for $20 \mathrm{~min}$ prior to rapid freezing. Five cells in each of these conditions were pooled, and the experiment was performed 3 times. The R15 neurons that were hyperpolarized have $41 \pm 7.3 \%$ more cAMP than those that were allowed to burst spontaneously. Presumably, the spontaneously bursting neurons are "loaded" with $\mathrm{Ca}^{2+}$, while the hyperpolarized neurons are relatively depleted of $\mathrm{Ca}^{2+}$. Therefore, measurements of cAMP in R15 are consistent with the notion that $\mathrm{Ca}^{2+}$ activates PDE in the spontaneously bursting cell.

\section{Discussion}

We have considered 3 possible mechanisms whereby $\mathrm{Ca}^{2+}$ could inactivate $I_{R}$ in neuron $R 15$ : 


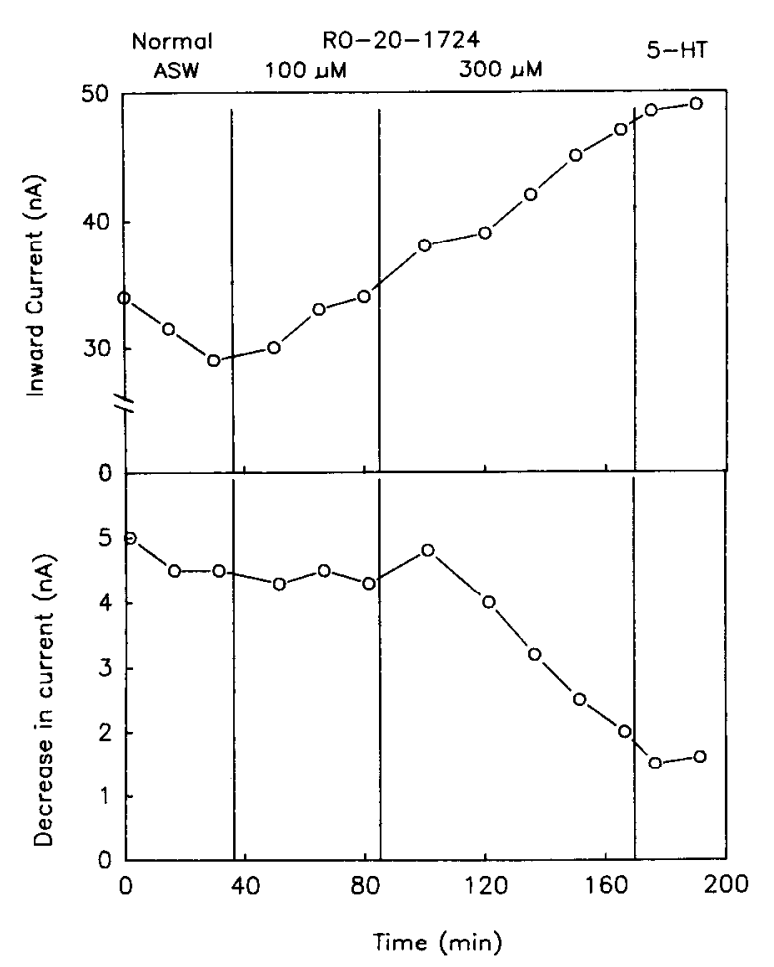

Figure 11. Effect of RO-20-1724 on the $\mathrm{Ca}^{2+}$-dependent inactivation of $I_{R} . I_{R}$ (top) and the inactivation of $I_{R}$ elicited by simulated bursts (bottom) were measured at $15 \mathrm{~min}$ intervals. RO-20-1724, $100 \mu \mathrm{M}$, increases $I_{R}$ somewhat without reducing inactivation. A volume of 300 $\mu \mathrm{M}$ greatly increases $I_{R}$ and does reduce inactivation. $I_{R}$ was measured by applying $400 \mathrm{msec}$ pulses from -75 to $-115 \mathrm{mV}$.

\section{Direct modulation of $I_{R}$ channels}

The evidence presented in this paper suggests that $\mathrm{Ca}^{2+}$ does not inactivate $I_{R}$ directly by interacting with $I_{R}$ channels. Increasing the magnitude of $I_{R}$ by adding agents that elevate cAMP (5-HT, forskolin, 8-PCPT-cAMP) leads to a paradoxical inhibition of the $\mathrm{Ca}^{2+}$-dependent inactivation of $\mathrm{I}_{R}$. This occurs even though each of these agents enhances the voltage-gated $\mathrm{Ca}^{2+}$ current. We did not attempt to measure the level of $\mathrm{Ca}^{2+}$ in neuron $\mathrm{R} 15$; hence it is possible that cAMP changes either the background concentration of $\mathrm{Ca}^{2+}$ or the $\mathrm{Ca}^{2+}$ buffering capacity of the cytoplasm, and it is possible that changes in these parameters contribute to the suppression of $I_{R}$ inactivation. The inhibition of inactivation does not appear to be caused by an acceleration of the recovery of $I_{R}$ following $\mathrm{Ca}^{2+}$ influx (Figs. 3, 4 ), and is not due to an insensitivity of modulated $I_{R}$ channels to $\mathrm{Ca}^{2+}$ (Fig. 6). In contrast, substances that increase cAMP do enhance the $\mathrm{Ca}^{2+}$-dependent inactivation of $\mathrm{I}_{\mathrm{Ca}}$ in $\mathrm{R} 15$ (Figs. 1-3; Levitan and Levitan, 1988), presumably by increasing both $\mathrm{Ca}^{2+}$ influx and the magnitude of $\mathrm{I}_{\mathrm{Ca}}$ available for inactivation. Hence, there appears to be an important difference between the way $\mathrm{Ca}^{2+}$ inactivates $\mathrm{I}_{\mathrm{R}}$ and $\mathrm{I}_{\mathrm{Ca}}$. Our results do not exclude a direct interaction of $\mathrm{Ca}^{2+}$ with $\mathrm{Ca}^{2+}$ channels as the critical step underlying $\mathrm{Ca}^{2+}$-dependent inactivation of $\mathrm{Ca}^{2+}$ currents. However, electrophysiological (Chad and Eckert, 1986; Armstrong and Eckert, 1987) and biochemical (Hosey et al., 1986) studies suggest that the $\mathrm{Ca}^{2+}$-dependent inactivation of at least some $\mathrm{Ca}^{2+}$ channels is not due to the direct binding of $\mathrm{Ca}^{2+}$, but rather to stimulation of a phosphatase that reverses the cAMP-dependent phosphorylation of these channels. It is of course possible

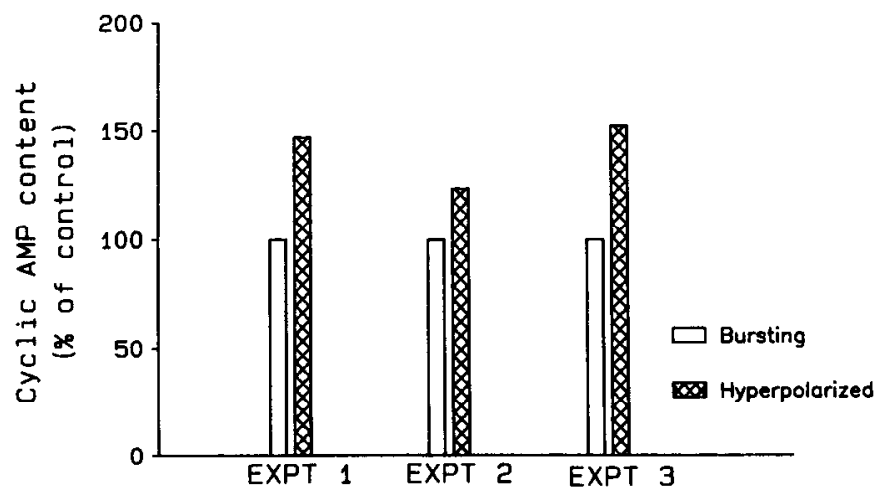

Figure 12. CAMP content of spontaneous bursting and hyperpolarized R 15 neurons. Three experiments were performed, each using 5 R 15 neurons in each of the 2 conditions. The isolated somata were pooled and 2 separate determinations were made with each group of 5 cells. CAMP content is normalized with respect to the spontaneously bursting neurons in each experiment.

that the $\mathrm{Ca}^{2+}$-dependent inactivation of $\mathrm{Ca}^{2+}$ currents in Aplysia neurons involves both direct and indirect mechanisms.

\section{Modulation of $I_{R}$ channels via activation of kinases or phosphatases}

We have no direct evidence bearing on the hypothesis that $\mathrm{Ca}^{2+}$ causes $I_{R}$ inactivation by activation of a $\mathrm{Ca}^{2+}$-sensitive protein kinase or phosphatase. Despite the evidence for an interaction between $\mathrm{Ca}^{2+}$ and cAMP (see below), $\mathrm{Ca}^{2+}$ could still exert its effect on $I_{R}$ by causing the phosphorylation of the same substrate that is phosphorylated by the cAMP-dependent protein kinase. $\mathrm{Ca}^{2+}$ - and cAMP-dependent protein kinases have been shown to cause dual phosphorylation of one subtrate protein (synapsin I), both at identical and at different sites on the protein, allowing for possible interactions between the 2 intracellular messengers at their target effector molecules (for review, see Nestler and Greengard, 1983). It is also possible that $\mathrm{Ca}^{2+}$ activates a phosphatase that dephosphorylates the substrate responsible for $I_{R^{-}}$ channel activation. This seems less likely, as is discussed below.

\section{Modulation of $I_{R}$ by inhibition of $C A M P$-dependent activation}

Our results support the hypothesis that $\mathrm{Ca}^{2+}$ causes the inactivation of $I_{R}$ by decreasing the cAMP-dependent activation of the current. $\mathrm{Ca}^{2+}$ influx not only inactivates the basal $\mathrm{I}_{\mathrm{R}}$, but also decreases $I_{R}$ that can be recruited by brief application of neuromodulators such as 5-HT (Fig. 7) and ELH, implying that $\mathrm{Ca}^{2+}$ inhibits the cAMP-dependent activation of $\mathrm{I}_{\mathrm{R}}$. Indeed, recent studies using a range of 5-HT concentrations have indicated that "loading" $\mathrm{R} 15$ with $\mathrm{Ca}^{2+}$ shifts the dose-response curve of the $I_{R}$ response to higher 5-HT concentrations without reducing the maximal response $(R . H$. Kramer, unpublished observations). In addition $\mathrm{Ca}^{2+}$-loading accelerates the recovery of $I_{R}$ to its basal level after the neuron has been briefly exposed to these neuromodulators, suggesting that $\mathrm{Ca}^{2+}$ can affect a step in the cAMP cascade that persists after the 5-HT has been washed away from the neuron. The component of the cAMP cascade that remains active after the removal of agonist seems to be located somewhere before the phosphorylated substratc (e.g., ion channel protein), as is suggested by studies using a specific inhibitor of cAMP-dependent protein kinase (PKI). Injection of Aplysia sensory neurons (Castellucci et al., 1982) and 
neuron R15 (J. Lemos and W. Adams, personal communication) with PKI rapidly reverses the effect of 5-HT on the modulated $\mathrm{K}^{+}$current, suggesting that the phosphorylation of the protein that regulates the current is labile, and that the continuous activity of the kinase is necessary to maintain the $\mathrm{K}^{+}$ channels in their modulated state (Castellucci et al., 1982). If the phosphorylated substrate that activates $I_{R}$ is short-lived in $\mathrm{R} 15$, then it is unlikely that $\mathrm{Ca}^{2+}$ acts at a step subsequent to the phosphorylation of this substrate. Hence, we consider it unlikely that a $\mathrm{Ca}^{2+}$-stimulated phosphatase is the primary locus at which $\mathrm{Ca}^{2+}$ acts to cause the inactivation of $I_{R}$, although we have no direct evidence that would rule out a contribution from such a mechanism.

There are 2 steps preceding phosphorylation at which $\mathrm{Ca}^{2+}$ has been shown to regulate cAMP metabolism. First, $\mathrm{Ca}^{2+}$, via calmodulin, regulates adenylate cyclase activity. The effect of $\mathrm{Ca}^{2+}$ on adenylate cyclase activity in both mammalian (Gnegy and Treisman, 1981) and Aplysia (Weiss and Drummond, 1985) tissues is biphasic: up to $10 \mu \mathrm{M} \mathrm{Ca}^{2+}$ activates the cyclase, while higher concentrations inhibit it. Conjoint activation of adenylate cyclase activity by agonists and $\mathrm{Ca}^{2+}$ (below $10 \mu \mathrm{M}$ ) has been proposed as a mechanism that enhances cAMP-dependent responses during associative conditioning (Abrams et al., 1985; Ocorr et al., 1985). The inhibition of the cyclase by $\mathrm{Ca}^{2+}$ concentrations exceeding $10 \mu \mathrm{M}$ could, in theory, contribute to the $\mathrm{Ca}^{2+}$-dependent inactivation of $I_{R}$ in $\mathrm{R} 15$, but whether $\mathrm{Ca}^{2+}$ ever exceeds this concentration in $\mathrm{R} 15$ is unknown.

The second step at which $\mathrm{Ca}^{2+}$ regulates cAMP metabolism is at the activation of PDE via calmodulin. Our results show that the Aplysia abdominal ganglion, and R15 in particular, contains a $\mathrm{Ca}^{2+} /$ calmodulin-sensitive $\mathrm{PDE}$, as well as a $\mathrm{Ca}^{2+}$. independent PDE. Multiple forms of PDE with different substrate specificities, kinetics, sensitivity to pharmacological agents, and regulation by $\mathrm{Ca}^{2+}$ have been identified previously in mammals (Wells and Hardman, 1977; Tanner et al., 1986; Weishaar et al., 1986) and invertebrates (Davis and Kauvar, 1984). The $\mathrm{Ca}^{2+} /$ calmodulin-activated PDE has been immunocytochemically localized to dendrites and somata of brain neurons, suggesting a postsynaptic function (Kincaid et al., 1987). In a variety of tissues, this enzyme is thought to be regulated by physiological changes in $\mathrm{Ca}^{2+}$, and now there is direct evidence that PDE is activated by physiological changes of $\mathrm{Ca}^{2+}$ in intact smooth muscle cells (Saitoh et al., 1985).

We propose that activation of $\mathrm{Ca}^{2+} /$ calmodulin-sensitive $\mathrm{PDE}$ is at least partly responsible for the inactivation of $I_{R}$ in neuron $R 15$. The $\mathrm{Ca}^{2+}$-dependent inactivation of $I_{R}$ is inhibited by the addition of the PDE inhibitor IBMX, and apparently this inhibition does not require a large increase in cAMP (Fig. 10). The observation that bursting pacemaker activity reduces CAMP content is consistent with the hypothesis that $\mathrm{Ca}^{2+}$ stimulates PDE activity. The inactivation of $I_{R}$ is also inhibited by adding RO-20-1724 (Fig. 11), a selective inhibitor of the $\mathrm{Ca}^{2+}$-independent PDE, but we suggest that RO-20-1724 only inhibits the inactivation of $I_{R}$ when an overwhelming concentration of $c A M P$ builds up in the neuron. The finding that RO-20-1724 increases $I_{R}$ without inhibiting the $\mathrm{Ca}^{2+} /$ calmodulin-sensitive PDE suggests that the $\mathrm{Ca}^{2+}$-independent PDE is important for maintaining the basal level of cAMP. Under the conditions used in our assays, there seems to be more $\mathrm{Ca}^{2+}$-independent than $\mathrm{Ca}^{2+}$ calmodulin-sensitive PDE activity in R15. The relative importance of these 2 enzymes in regulating cAMP levels in the intact cell remains to be determined.
Thus, the most likely mechanism by which intracellular $\mathrm{Ca}^{2+}$ leads to an inactivation of $I_{R}$ is via an interaction with cAMP metabolism. The $\mathrm{Ca}^{2+}$-dependent inactivation of $I_{R}$ could be just one of the effects of the interplay between $\mathrm{Ca}^{2+}$ and cAMP in R15. Further studies of interactions between intracellular messenger systems are likely to reveal additional consequences important for the short- and long-term function of neurons.

\section{References}

Abrams, T. W., L. Eliot, Y. Dudai, and E. R. Kandel (1985) Activation of adenylate cyclase in Aplysia neural tissue by $\mathrm{Ca}^{2+} /$ calmodulin, a candidate for an associative mechanism during conditioning. Soc. Neurosci. Abstr. 11: 797

Adams, W. B., and I. B. Levitan (1985) Voltage and ion dependences of the slow currents which mediate bursting in Aplysia neurone R15. J. Physiol. (Lond.) 360: 69-93.

Armstrong, D., and R. Eckert (1987) Voltage-activated calcium channels that must be phosphorylated to respond to membrane depolarization. Proc. Natl. Acad. Sci. USA 84: 2518-2522.

Benson, J. A., and I. B. Levitan (1983) Serotonin increases an anomalously rectifying $\mathrm{K}^{+}$current in the Aplysia neuron R15. Proc. Natl. Acad. Sci. USA 80: 3522-3525.

Brostrom, M. A., C. O. Brostrom, B. M. Breckenridge, and D. J. Wolff (1978) Calcium-dependent regulation of brain adenylate cyclase. Adv. Cyclic Nucleotide Res. 9: 85-99.

Castellucci, V. F., A. Nairn, P. Greengaard, and J. H. Schwartz (1982) Inhibitor of adenosine $3^{\prime}: 5^{\prime}$-monophosphate-dependent protein kinase blocks presynaptic facilitation in Aplysia. J. Neurosci. 2: 1673 1681 .

Cedar, H., and J. H. Schwartz (1972) Cyclic adenosine monophosphate in the nervous system of Aplysia californica. II: Effect of serotonin and dopamine. J. Gen. Physiol. 60: 570-587.

Chad, J. E., and R. Eckert (1986) An enzymatic mechanism for calcium current inactivation in dialyzed Helix neurones. J. Physiol. (Lond.) $378 \cdot 31-51$

Davis, R. L., and L. M. Kauvar (1984) Drosophila cyclic nucleotide phosphodiesterases. Adv. Cyclic Nucleotide Res. 16: 393-402.

DeLorenzo, R. D. (1984) Calmodulin systems in neuronal excitability. Ann. Neurol. 16: 1104-1145.

Drummond, A. H., J. A. Benson, and I. B. Levitan (1980) Serotonininduced hyperpolarization of an identified Aplysia neuron is mediated by cyclic AMP. Proc. Natl. Acad. Sci. USA 77: 5013-5017.

Eckert, R., and J. E. Chad (1984) Inactivation of Ca channels. Prog. Biophys. Mol. Biol. 44: 215-267.

Giller, E., and J. H. Schwartz (1971) Choline acetyltransferase in identified neurons of abdominal ganglion of Aplysia californica. J. Neurophysiol. 34: 93-107.

Gnegy, M., and G. Treisman (1981) Effect of calmodulin on dopamine-sensitive adenylate cyclase activity in rat striatal membranes. Mol. Pharmacol. 19: 256-263.

Gorman, A. L. F., A. Hermann, and M. V. Thomas (1982) Ionic requirements for membrane oscillations and their dependence on the calcium concentration in a molluscan pace-maker neurone. J. Physiol. (Lond.) 327: 185-217.

Greengard, P. (1978) Phosphorylated proteins as physiological effectors. Science 199: 146-152.

Gunning, R. (1987) Increased numbers of ion channels promoted by an intracellular second messenger. Science 235: 80-82.

Hosey, M. M., M. Borsetto, and M. Lazdunski (1986) Phosphorylation and dephosphorylation of dihydropyridine sensitive voltage-dependent calcium channel in skeletal muscle membranes by cAMP- and Ca-dependent processes. Proc. Natl. Acad. Sci. USA 83: 3733-3737.

Kincaid, R. L., C. D. Balaban, and M. L. Billingsley (1987) Differential localization of calmodulin-dependent enzymes in rat brain: Evidence for selective expression of cyclic nucleotide phosphodiesterase in specific neurons. Proc. Natl. Acad. Sci. USA 84: 1118-1 122.

Kramer, R. H., and I. B. Levitan (1987) Physiological interaction between calcium and cyclic AMP in an Aplysia bursting neuron. Soc. Neurosci. Abstr. 13: 1439.

Kramer, R. H., and I. B. Levitan (1988) Calcium-dependent inactivation of a potassium current in the Aplysia neuron R15. J. Neurosci. 8: 1796-1803.

Kramer, R. H., and R. S. Zucker (1985a) Calcium-dependent inward 
current in Aplysia bursting pace-maker neurones. J. Physiol. (Lond.) 362: 107-130.

Kramer, R. H., and R. S. Zucker (1985b) Calcium-induced inactivation of calcium current causes the interburst hyperpolarization of Aplysia bursting pacemaker neurones. J. Physiol. (Lond.) 362: 131160.

Kramer, R. H., E. S. Levitan, and I. B. Levitan (1988) Physiological interaction between calcium and cyclic AMP in an Aplysia bursting pacemaker neuron. In Ion Channel Modulation, A. D. Grinnell, D. L. Armstrong, and M. B. Jackson, eds., Plenum, New York (in press).

Lemos, J. R., W. B. Adams, I. Novak-Hofer, J. A. Benson, and I. B. Levitan (1986) Regulation of neuronal activity by protein phosphorylation. In Neural Mechanisms of Conditioning, D. L. Alkon and C. D. Woody, eds., pp. 397-420, Plenum, New York.

Levitan, E. S., and I. B. Levitan (1988) Serotonin acting via cyclic AMP enhances both the hyperpolarizing and depolarizing phases of bursting pacemaker activity in the Aplysia neuron R15. J. Neurosci. 8: 1152-1161.

Levitan, E. S., R. H. Kramer, and I. B. Levitan (1987) Augmentation of bursting pacemaker activity in Aplysia neuron R 15 by egg-laying hormone is mediated by a cyclic AMP-dependent increase in $\mathrm{Ca}^{2+}$ and $\mathrm{K}^{+}$currents. Proc. Natl. Acad. Sci. USA 84: 6307-6311.

Levitan, I. B. (1978) Adenylate cyclase in isolated Helix and Aplysia neuronal cell bodies: Stimulation by scrotonin and peptide-containing extract. Brain Res. 154: 404-408.

Levitan, I. B. (1985) Phosphorylation of ion channels. J. Membr. Biol. 87: 177-190.

Levitan, I. B., and A. H. Drummond (1980) Neuronal serotonin receptors and cyclic AMP: Biochemical, Pharmacological and electrophysiological analysis. In Neurotransmitters and their Receptors, $\mathrm{U}$ Z. Littauer, Y. Dudai, I. Silman, V. I. Teichberg, and Z. Vogel, eds., pp. 163-176, Wiley, Chichester, UK.

Lotshaw, D. P., E. S. Levitan, and I. B. Levitan (1986) Fine tuning of neuronal electrical activity: Modulation of several ion channels by intracellular messengers in a single identified nerve cell. J. Exp. Biol. 124: 307-322.

Moczydlowski, E., and R. Latorre (1983) Gating kinetics of $\mathrm{Ca}^{2+}$ activated potassium channels from rat muscle incorporated into planar lipid bilayers: Evidence for two voltage-dependent $\mathrm{Ca}^{2+}$ binding reactions. J. Gen. Physiol. 82: 511-542.
Nakamura, T., and G. H. Gold (1987) A cyclic nucleotide-gated conductance in olfactory receptor cilia. Nature $325: 442-444$.

Nestler, E. J., and P. Greengard (1983) Protein phosphorylation in the brain. Nature 204: 583-588.

Ocorr, K. A., E. T. Walters, and J. H. Byrne (1985) Associative conditioning analog selectively increases cAMP levels of tail sensory neurons in Aplysia. Proc. Natl. Acad. Sci. USA 82: 2548-2552.

Saitoh, Y., J. G. Hardman, and J. N. Wells (1985) Differences in the association of calmodulin with cyclic nucleotide phosphodiesterase in relaxed and contracted arterial strips. Biochemistry 24: 1613-1618.

Sakakibara, M., D. L. Alkon, R. DeLorenzo, J. R. Goldenring, J. T. Neary, and E. Heldman (1986) Modulation of calcium-mediated inactivation of ionic currents by $\mathrm{Ca}^{2+} /$ calmodulin-dependent protein kinase II. Biophys. J. 50: 319-327.

Seamon, K. B., W. Padgett, and J. X. Daly (1981) Forskolin: Unique diterpene activator of adenylate cyclase in membranes and intact cells. Proc. Natl. Acad. Sci. USA 78: 3363-3367.

Tanner, L. I., T. K. Harden, J. N. Wells, and M. W. Martin (1986) Identification of the phosphodiesterase regulated by muscarinic cholinergic receptors of $1321 \mathrm{~N} 1$ human astrocytoma cells. Mol. Pharmacol. 29: 455-460.

Walter, M. F., and J. A. Kiger (1984) The dunce gene of Drosophila: Roles of $\mathrm{Ca}^{2+}$ and calmodulin in adenosine $3^{\prime}: 5^{\prime}$-cyclic monophosphate-specific phosphodiesterase activity. J. Neurosci. 4: 495-501.

Weishaar, R. E., S. D. Burrows, D. C. Kobylarz, M. M. Quade, and D. B. Evans (1986) Multiple molecular forms of cyclic nucleotide phosphodiesterase in cardiac and smooth muscle and in platelets. Biochem. Pharmacol. 35: 787-800.

Weiss, S., and G. I. Drummond (1985) Biochemical properties of adenylate cyclase in the gill of Aplysia. Comp. Biochem. Physiol. 80B: 251-255.

Weiss, B., and R. M. Levin (1978) Mechanism for selectively inhibiting the activation of cyclic nucleotide phosphodiesterase and adenylate cyclase by antipsychotic agents. Adv. Cyclic Nucleotide Res. 9: 285-303.

Wells, J. N., and J. G. Hardman (1977) Cyclic nucleotide phosphodiesterases. Adv. Cyclic Nucleotide Res. 8: 119-143.

Wolff, D. A., and C. O. Brostrom (1979) Properties and function of the calcium-dependent regulator protein. Adv. Cyclic Nucleotide Res. 11: $28-88$. 